\title{
Kinetic modelling of acrylamide formation during the finish-frying of french fries with variable maltose content
}

Article

Accepted Version

Creative Commons: Attribution-Noncommercial-No Derivative Works 4.0

Balagiannis, D. P., Mottram, D. S., Higley, J., Smith, G., Wedzicha, B. L. and Parker, J. K. (2019) Kinetic modelling of acrylamide formation during the finish-frying of french fries with variable maltose content. Food Chemistry, 284. pp. 236244. ISSN 0308-8146 doi:

https://doi.org/10.1016/j.foodchem.2019.01.075 Available at https://centaur.reading.ac.uk/81730/

It is advisable to refer to the publisher's version if you intend to cite from the work. See Guidance on citing.

To link to this article DOI: http://dx.doi.org/10.1016/j.foodchem.2019.01.075

Publisher: Elsevier

All outputs in CentAUR are protected by Intellectual Property Rights law, including copyright law. Copyright and IPR is retained by the creators or other copyright holders. Terms and conditions for use of this material are defined in the End User Agreement. 


\section{CentAUR}

Central Archive at the University of Reading

Reading's research outputs online 


\section{Kinetic modelling of acrylamide formation during the finish-frying of}

\section{2 french fries with variable maltose content}

3

4 Dimitrios P. Balagiannis ${ }^{\mathrm{a}}$, Donald S. Mottram ${ }^{\mathrm{a}}$, Jeremy Higley ${ }^{\mathrm{b}, 1}$, Gordon Smith ${ }^{\mathrm{b}, 2}$,

5 Bronislaw L. Wedzicha ${ }^{\mathrm{c}}$, Jane K. Parker ${ }^{\mathrm{a}, *}$

6

$7 \quad$ aDepartment of Food and Nutritional Sciences, University of Reading, Whiteknights, Reading

$8 \quad$ RG6 6AP, UK

$9 \quad$ bonAgra Foods, Six ConAgra Drive, Omaha, NE 68102, United States

$10{ }^{\mathrm{c}}$ School of Food Science and Nutrition, University of Leeds, Leeds LS2 9JT, UK

11

12

$18{ }^{1}$ Current address: Lamb Weston Holdings Inc., 856 Russet Street, Twin Falls, ID 83301

$19{ }^{2}$ Current address: Grain Science and Industry Department, Kansas State University,

20 Manhattan, KS 66506

21

22 *corresponding author: Email: j.k.parker@ reading.ac.uk, Tel +44 1183787455 
23 Abstract

24 In light of a recent update in EU regulations governing levels of acrylamide in foodstuffs, further understanding of the role of different precursors is fundamental to extending mitigation strategies into a wider product range. Kinetic modelling was used to investigate the role of maltose in the formation of acrylamide during the finish-frying of french fries. The maltose concentration of raw white potato strips was systematically increased to observe the effect of this reducing disaccharide on acrylamide formation. A mathematical model, incorporating glucose, fructose and maltose and based on known Maillard reaction pathways, was developed which showed that acrylamide

31 formation from maltose only contributed $<10 \%$ to the total acrylamide. An additional kinetic model allowed for the formation of acrylamide directly from sugar-asparagine glycoconjugates. This model suggested that under these conditions, it is unlikely that acrylamide is formed directly from the maltose-asparagine conjugate.

40 Keywords: potato fries, maltose, acrylamide, kinetic modelling, Maillard, glycoconjugates 


\section{Introduction}

Since the discovery of high amounts of acrylamide, a probable carcinogen (IARC, 1994), in processed foods, there has been a considerable effort to reduce the acrylamide content in processed products either by manipulating the precursors and the processing conditions, or by obtaining raw materials with low asparagine content (Halford, Curtis, Muttucumaru, Postles, Elmore, \& Mottram, 2012). In light of new EU regulations (Commision Regulation (EU) 2017/2158) which came into force in 2017 establishing tighter mitigation measures and benchmark levels for the reduction of acrylamide in food, a concerted approach to acrylamide mitigation is required. Further understanding of the role of different precursors under different conditions is fundamental to extending mitigation strategies into a wider product range.

Maltose is an important disaccharide found in many foods, and is formed from the breakdown of starch by $\beta$-amylases which are found in sweet potatoes, soya beans and germinating grains such as barley and wheat. It is a reducing sugar and our hypothesis is that maltose will contribute to the formation of acrylamide during high temperature processing of asparagine rich foods. Although the breakdown pathways of disaccharides during the Maillard reaction are well documented (Pischetsrieder \& Severin, 1996; Smuda \& Glomb, 2011), only a limited number of studies have focused on the role of disaccharides and their corresponding Maillard-derived intermediates in the formation of acrylamide (Koutsidis, De la Fuente, Dimitriou, Kakoulli, Wedzicha, \& Mottram, 2008). In this study, we look at the relative contribution of maltose to acrylamide formation during a typical food manufacturing process and compare the relative rates of formation from glucose, fructose and maltose under different processing conditions. Combining established mechanisms for acrylamide formation from monosaccharides and for the maltose-induced Maillard reaction, this leads us to propose the following three possible pathways for maltose-induced acrylamide formation : 1) breakdown of maltose via the Maillard reaction to provide a pool of reactive carbonyl 
maltose to release glucose and subsequent formation of acrylamide from glucose and glucose breakdown products; 3) direct breakdown of the maltose-asparagine glycoconjugate.

Multiresponse kinetic modelling is an effective technique to study the Maillard reaction (Balagiannis, 2014; Parker, 2013; van Boekel, 2008). It can be used predictively to obtain quantitative insight into complex reactions, but it can also serve as a means of probing and testing different mechanistic pathways, thus providing strategies for controlling the reaction and, in this case, minimising acrylamide. In particular, the kinetics of acrylamide formation has been studied in simple mixtures of asparagine and reducing sugars, usually monosaccharides (De Vleeschouwer, Van der Plancken, Van Loey, \& Hendrickx, 2008a, 2008b, 2009a, 2009b; Knol, Linssen, \& van Boekel, 2010; Knol, Van Loon, Linssen, Ruck, van Boekel, \& Voragen, 2005) under various process conditions. Van der Fels-Klerx and coworkers (Nguyen, Van der Fels-Klerx, Peters, \& van Boekel, 2016; Nguyen, Van der Fels-Klerx, \& van Boekel, 2017; Van Der Fels-Klerx et al., 2014) extended this approach into biscuits, whilst Parker, Balagiannis, Higley, Smith, Wedzicha, \& Mottram (2012) used this approach in french fries taking into account the full complement of free amino acids and reducing sugars in a complex food matrix. Parker et al. (2012) used a standard protocol to manipulate the glucose and fructose levels in french fries, which were then processed in a pilot-scale commercial fryer under different frying conditions. Uniquely, this model also accounted for the moisture and heat transfer phenomena, as described for a one-dimensional infinite slab by Ni and Datta (1999). Recently, this model was revisited, upgraded and extended to approximate the mass and heat transfer events on a three dimensional basis (Balagiannis et al., 2016).

In this study, the same process was used in order to investigate the role of maltose in acrylamide formation during the finish frying of white potato fries. Although white potatoes are not a natural source of maltose, they were selected for this study because the matrix can serve as a versatile substrate in which to manipulate and study the effects of maltose content on the kinetics of acrylamide formation. One further advantage was the fact that the behaviour of glucose and 
fructose, and the heat and moisture transfer phenomena, have already been determined in white potato fries (Parker et al., 2012), providing an ideal starting point for studying the relative contribution of maltose, in comparison to glucose and fructose.

The aims of this study were to use multi response kinetic modeling to understand the role of maltose in acrylamide formation in a real product, using French fries with variable maltose content prepared under pilot-scale manufacturing conditions. By incorporation of similar data using glucose and fructose from Parker et al. (2012), we developed one model that can explain and compare the relative contribution from each of the sugars during acrylamide formation. Further to the role of maltose, we also take the opportunity provided by this rich data set to develop a better understanding of the mechanism of acrylamide formation by considering both the specific amino acid pathway where reducing sugars react directly with asparagine to form acrylamide, and a generic amino acid pathway where reactive precursors are formed via the Maillard reaction.

\section{Materials and methods}

\subsection{Materials}

Ranger Russet potatoes were obtained from the 2013 crop and stored at $7-9{ }^{\circ} \mathrm{C}$ until use. All chemicals were supplied as described by Parker et al. (2012).

\subsection{Preparation of french fries with variable maltose content}

Ranger Russet potatoes were treated and processed as described by Parker et al. (2012) except that the glucose and fructose dips were replaced by a maltose dip. The commercial production of french fries involves a multi-step process which was reproduced as closely as possible on a pilot scale.

$$
\text { Briefly, the raw potatoes from harvest or storage were washed, peeled, preheated }\left(54{ }^{\circ} \mathrm{C}, 30 \mathrm{~min}\right)
$$
and cut into strips. The cross section of the raw potato strips was $7.5 \times 7.5 \mathrm{~mm}$ and the length varied between 7.5 and $12.5 \mathrm{~cm}$. Subsequent blanching at $80^{\circ} \mathrm{C}$ for $10 \mathrm{~min}$ causes some leaching of sugars and was followed by a dipping step where the potato strips were immersed into a maltose solution of varying concentration $\left(70-75^{\circ} \mathrm{C}, 30 \mathrm{~s}\right)$. The loss of sugars during blanching, and the requirement to restore their concentration, is a part of the process that allows the control of the Maillard reaction, 
thus influencing colour and acrylamide formation. The blanched potato strips were dipped in maltose solutions of the following concentrations: $0 \%$ (only water), 1, 2, 3, 4 and $14 \%(\mathrm{w} / \mathrm{v})$. The outlying value of $14 \%$ was chosen to achieve a final maltose content similar to that of blanched sweet potato strips. In sweet potatoes, the maltose increases up to $\sim 2 \%$ during the manufacturing process, depending on the variety and the processing conditions (Takahata, Noda, \& Nagata, 1994). Application of a $14 \%$ dip to white potato strips took the maltose content up to $1.4 \%$ (wet weight) in the blanched strip. During blanching and dipping there was an uptake of $\sim 10 \%$ of water which was removed by a subsequent drying step $\left(60^{\circ} \mathrm{C}, 10 \mathrm{~min}\right)$. The potato strips were then par-fried $\left(190{ }^{\circ} \mathrm{C}\right.$, $50 \mathrm{~s})$ in canola oil, packaged and frozen $\left(-20^{\circ} \mathrm{C}\right)$ before finish-frying in canola oil. Typically finishfrying is carried out for 2-5 min, to an end point based on the desirable colour, texture, and flavour. Each batch $(\sim 220 \mathrm{~g})$ was finish-fried at $165^{\circ} \mathrm{C}$ for 10 different time points $(0.5,1.0,1.5,2.0,2.5$, 3.0, 3.5, 4.0, 4.5 and $5.0 \mathrm{~min})$. Immediately after frying, the samples were submerged in liquid nitrogen to prevent any further reaction, and stored at $-20{ }^{\circ} \mathrm{C}$ until further analysis. A similar process was followed for a second batch of potatoes that was dipped in a solution of $2 \%$ maltose and then fried at 175 and $185^{\circ} \mathrm{C}$.

\subsection{Chemical analysis}

Acrylamide concentration was determined using the method described by Parker et al. (2012) using an SPE clean-up procedure, analysis by LC-MS/MS and quantification using ${ }^{13} \mathrm{C}_{3}$-labeled acrylamide as an internal standard.

The analysis of sugars was performed by HPLC according to the method reported by Parker et al. (2012). The concentration of glucose, fructose, maltose, and sucrose in samples was calculated via external calibration with authentic standards.

Free amino acids were measured via derivatisation as described by Parker et al. (2012). In summary, the free amino acids Asn, Gln, Arg, Ala, Gla, Val, Asp, Ser, Lys, Phe, Tyr, Thr, Ile, Met, Pro, His, Leu, and Gly were derivatised by $o$-phthalaldehyde and 9-fluorenylmethoxycabonyl chloride in an autosampler immediately before injection in an Agilent HPLC 1100 series. 
Analysis of water and total fat content were performed as described by Parker et al. (2012). Briefly, moisture was determined by oven drying $2 \mathrm{~g}$ of sample until constant weight in a fan oven at 125

${ }^{\circ} \mathrm{C}$. Fat was extracted, hydrolysed and methylated to produce fatty acid methyl esters which were quantitated by GC-MS.

Colour formation was assessed with an Agtron E-30 Analyzer (Agtron Inc., Reno, NV) as described in Parker et al. (2012).

\subsection{Kinetic modelling}

Multiresponse modelling and model simulations were performed using the Athena Visual Studio software package (Athena Visual Software Inc., Naperville, IL).

\section{Results and discussion}

\subsection{General observations}

The maltose, glucose, fructose, sucrose, free amino acids and acrylamide contents were measured in order to monitor the acrylamide formation in relation to the initial concentration of Maillard reaction precursors. The data are all displayed graphically in supplementary Figure S1. The concentration of sucrose did not alter during the course of the reaction (results not shown). The temperatures that are typically applied during frying far exceed $100{ }^{\circ} \mathrm{C}$, which results in a continuous evaporation and loss of moisture. Furthermore, the fried strips absorb oil during frying: $70-80 \%$ of the oil that is detected in the final finish-fried product adheres to the surface of the fry, while the other $20-30 \%$ is oil that is trapped in the crust (Aguilera \& Gloria-Hernandez, 2000). The experimental data confirmed that the longer the frying time, the greater the loss of moisture and the higher the amount of oil that was absorbed. In order to compare the trend of the components of interest with time, it was necessary to normalise their concentration by removing any effect introduced by their moisture and the fat content. Thus, throughout this paper, the concentration of the analytes is reported on a defatted dry weight basis.

The experiment was performed with two different batches of white potatoes. In the first batch, the concentration of maltose dip ranged from $0-14 \%$ and the fries were processed at $165{ }^{\circ} \mathrm{C}$ (samples 
M0, M1, M2, M3, M4 and M14, Figure 1). In samples M0, M1, M2 and M3, all precursors decreased over time, and there was a continuous increase in acrylamide. However, in samples M4 and M14, i.e. the two samples with the highest concentration of maltose, glucose either remained stable (M4) or there was a small increase with time (M14). This is probably due to the formation of glucose from the degradation of maltose, which in the samples with high maltose may occur faster than the reaction of glucose with amino groups, thus the net result is a small accumulation of glucose. The second batch of white potatoes was dipped in a $2 \%$ maltose solution and then samples were finish-fried at either $175^{\circ} \mathrm{C}\left(\mathrm{M} 2{ }^{\prime} 175\right)$ or $185^{\circ} \mathrm{C}\left(\mathrm{M} 2{ }^{\prime} 185\right)$. These two potato batches had different concentrations of precursors at the start: the raw fries in the first batch had on average 12.7 $\mathrm{mmol} / \mathrm{kg}$ dry weight glucose and $131 \mathrm{mmol} / \mathrm{kg}$ dry weight of total free amino acids, whilst the raw fries in the second batch had half as much glucose $(6.1 \mathrm{mmol} / \mathrm{kg}$ dry weight $)$ but almost double total free amino acids (238 mmol/kg dry weight). These differences, whilst not immediately comparable with the previous batch, provide additional information for the kinetic modelling and strengthen the model.

Even though the maltose dip levels varied from $0 \%$ to $14 \%$, the range of acrylamide formation was narrow. Sample M0 reached a maximum of $5.4 \mu \mathrm{mol} / \mathrm{kg}$ dry weight, as a result of the reaction of the endogenous fructose and glucose present in the potato strips. Sample M1 had a maximum of $13.4 \mu \mathrm{mol} / \mathrm{kg}$ dry weight, while the other samples (i.e. M2, M3, M4 and M14) had similar final acrylamide concentrations in the range $20-24 \mu \mathrm{mol} / \mathrm{kg}$ dry weight. Beyond the $2 \%$ dip, further increases in maltose concentration seem to have little impact on acrylamide formation, and this was not due to exhaustion of the asparagine. In a similar experiment, when the glucose and fructose dips varied up to just $2 \%$, the final concentration of acrylamide was much higher, ranging from $8.2-86$ $\mu \mathrm{mol} / \mathrm{kg}$ dry weight (Parker et al., 2012). It is striking that the amount of acrylamide formed in the batches with 2, 3, 4 and 14\% maltose dip concentrations was similar even though it corresponded to different degrees of maltose consumption (Table 1). For example, the fries with $2 \%$ and $14 \%$ maltose dip showed similar acrylamide formation (20.1 and $20.8 \mu \mathrm{mol} / \mathrm{kg}$ dry weight respectively), 
which corresponded to different losses of maltose (10.7 and $52.4 \mu \mathrm{mol} / \mathrm{kg}$ dry weight respectively).

197 Similarly, the study of the above systems in relation to colour formation (Table 1) showed that the

198 fries with added maltose developed less colour than the systems with added glucose or fructose. In

199 fact, after 5 min of frying, the samples which had been dipped in $14 \%$ maltose and $2 \%$ fructose had

200 a similar colour, but M14 has consumed twice as much sugar but formed a fraction of the

201 acrylamide.

202 It is likely that the maltose is converted into colourless higher molecular weight compounds. Frank 203 and Hofmann (2000) have shown that colour formation in maltose is hindered by the 1,4-glycosidic 204 link which is unhydrolysable under typical food preparation conditions. The maltose-derived glycosides are colourless compared to their monosaccharide counterparts which undergo further eliminations to generate coloured aglycones. Maltose also forms anhydrosugars, furosine and unreactive maltose specific compounds as suggested by Hollnagel and Kroh (2000) or other

208 heterocycles with the 1-4 glycosidic link still intact, as shown by Kramhoeller, Pischetsrieder, \& 209 Severin (1993). Hollnager and Kroh (2000) report that the major intermediate formed from maltose 210 degradation in a dry system at $100{ }^{\circ} \mathrm{C}$ was 1,4 -didoxyhexosulose $(1,4 \mathrm{DDH})$ and this built up to 211 concentrations of $18 \mathrm{~mol} \%$ in relation to maltose. It is reactive in terms of condensations reactions, 212 colour formation and the formation of heterocycles. However, they reported almost insignificant 213 amounts of C2/ C3 $\alpha$-dicarbonyls and $\alpha$-hydroxycarbonyls, which may explain the formation of 214 relatively little acrylamide. No-one as yet has shown the reactivity of 1,4DDH (an $\alpha$-dicarbonyl) 215 towards acrylamide formation. It seems that in french fries, the addition of maltose by dipping from 216 the level of $2 \%$ onwards does not affect significantly the formation of acrylamide, at least not as 217 much as it is affected by the addition of different levels of glucose or fructose shown by Parker et 218 al., (2012).

219 To conclude, during frying of potato strips, maltose was less effective than glucose and fructose, in 220 relation to the formation of Maillard products and acrylamide. This is in agreement with the fact 221 that in Maillard browning, disaccharides are less reactive than monosaccharides (Lingnert, 1990; 
Wedzicha \& Kedward, 1995). In addition, Koutsidis et al. (2008) reported that maltose was less potent than glucose and fructose with respect to acrylamide formation in a low-moisture waxy maize starch model system that was heated at $160{ }^{\circ} \mathrm{C}$.

\subsection{Developing the kinetic mechanism}

Given the complexity of the reactions involved, one approach to gaining a better understanding of these two pathways is to mathematically model the process based on the known chemistry of the reactions. Modelling a complex reaction such as acrylamide formation is a challenging task. An effective approach is to identify the few rate limiting steps that regulate the kinetic behaviour of the reaction and develop a mathematical model based on them. As a result, the dense network of subreactions that constitute a complex reaction are reduced to a limited number of kinetically important steps. Each kinetic step incorporates several chemical pathways on the basis that the rate of a group of reactions is determined by the speed of the slowest step. This approach has been applied successfully on several occasions in the field of Maillard chemistry and acrylamide formation. (Balagiannis et al., 2016; Balagiannis, Parker, Pyle, Desforges, Wedzicha, \& Mottram, 2009; Brands \& van Boekel, 2002; De Vleeschouwer et al., 2008b; Knol et el., 2005; Low, 2006; Martins \& van Boekel, 2004; Parker et al., (2012); Wedzicha, Mottram, Elmore, Koutsidis, \& Dodson, 2005). In earlier work on monosaccharides, we initially expressed the complex chemistry of acrylamide formation in relation to glucose and fructose in a few kinetic steps which included both the generic and specific amino acid pathways. However, there was high uncertainty in the kinetic parameters, particularly those driving the split between the generic and specific amino acid pathway, so a simpler model was published where these two pathways were collapsed into one, incorporating two kinetically important intermediates (Parker et al., 2012). Subsequent iterations of the model took into account the fact that more acrylamide is likely to be formed at the edges and corners of the fries, as is observed anecdotally by the greater colour formation at the edges and corners of the fries (Balagiannis et al., 2016). 
247 For the purpose of the present study, the previously published kinetic mechanism (Balagiannis et 248 al., 2016) was the starting point for development of a new model incorporating maltose. Several 249 modelling trials indicated that the estimates could be improved if the transition from glucose to a group of intermediates (Int2) was expressed by just one kinetic step instead of two. Furthermore, it is well documented that Maillard reaction intermediates that contain an intact sugar backbone fragment via retroaldolisation and oxidative fission reactions (Nursten, 2005) producing $\alpha$ dicarbonyls, $\alpha$-hydroxycarbonyls or acids from the reducing terminus of the sugar, and tetroses and trioses from the other end. These highly reactive compounds readily react with free amino acids. This molar relationship was included in the updated kinetic mechanism and was expressed by parameter $p$ which reflects the fact that the number of moles of Int 2 formed may be greater than the number of moles of glucose lost. The new mechanism accounted for a larger consumption of free amino acids during the reaction of Int 2 to form acrylamide and Maillard products, removing the necessity for the reaction previously associated with $\mathrm{k}_{\mathrm{aa}}$ which had been included in previous models to account for the undefined loss of free amino acids (Balagiannis et al., 2016; Parker et al., 2012).

\subsection{Incorporation of maltose into the kinetic model}

263 The kinetic mechanism was then expanded to include the chemistry and the kinetics of acrylamide 264 formation in relation to maltose. This was achieved by taking into account the study by Mundt and 265 Wedzicha (2005). These authors modelled the formation of melanoidins in a solution of $0.2 \mathrm{M}$ sodium acetate/glacial acid buffer ( $\mathrm{pH} 5.5)$, containing equimolar amounts of maltose $(0.25 \mathrm{M})$ and glycine, which was heated at $70{ }^{\circ} \mathrm{C}$ for several time points. They followed a radiochemical approach to propose a kinetic mechanism which described how maltose participates in the Maillard reaction.

269 In summary, they suggested that maltose reacts with glycine to form an intermediate which breaks 270 down to glucose and a second reactive intermediate, identified by Hollnager et al. (2000) as 1,4

271 DDH. The latter reacts further to form melanoidins via Int2. Hence, we propose Kinetic Mechanism 2721 (Figure 2) which shows how maltose, glucose and fructose participate in the formation of 
273 acrylamide. In Kinetic Mechanism 1 the role of maltose is dual: on the one hand, maltose itself (as a

274 reducing sugar) participates in the Maillard reaction and acrylamide formation, through a three-step

275 process and the formation of two pools of intermediates, Int $1_{\text {mal }}$ and Int (Pathway 1$)$. On the other

276 hand, one glucose molecule is released from Int $1_{\text {mal }}$ through a "peel off" mechanism, (Mundt and

277 Wedzicha, 2005) and maltose contributes to the formation of acrylamide via the glucose and

278 fructose (Pathway 2). The following differential equations are derived from Kinetic Mechanism 1

279 (Figure 2) and comprise Model 1.

280

$\frac{\mathrm{d}[\mathrm{Glu}]}{\mathrm{dt}}=-\mathrm{k}_{1}[\mathrm{Glu}][\mathrm{FAA}]+\mathrm{k}_{2 \mathrm{mal}}\left[\mathrm{Int} 1_{\mathrm{mal}}\right]-\mathrm{k}_{8}[\mathrm{Glu}]$

$281 \frac{\mathrm{d}[\mathrm{Fru}]}{\mathrm{dt}}=-\mathrm{k}_{6}[\mathrm{Fru}]+\mathrm{k}_{8}[\mathrm{Glu}]$

$282 \frac{\mathrm{d}[\mathrm{Mal}]}{\mathrm{dt}}=-\mathrm{k}_{1 \mathrm{mal}}[\mathrm{Mal}][\mathrm{FAA}]$

$\frac{\mathrm{d}[\mathrm{FAAs}]}{\mathrm{dt}}=-\mathrm{k}_{3}[\operatorname{Int} 2][\mathrm{FAA}]$

$\frac{\mathrm{d}[\mathrm{Asn}]}{\mathrm{dt}}=-\mathrm{k}_{3}[\operatorname{Int} 2][$ Asn $]$

$\frac{\mathrm{d}[\mathrm{Acr}]}{\mathrm{dt}}=\mathrm{k}_{3}[$ Int2] $]$ Asn $] * \mathrm{~F}_{\text {Asn }} *$ Asn

$\frac{\mathrm{d}\left[\operatorname{Int} 1_{\mathrm{mal}}\right]}{\mathrm{dt}}=\mathrm{k}_{1 \mathrm{mal}}[\mathrm{Mal}][\mathrm{FAA}]-\mathrm{k}_{2 \mathrm{mal}}\left[\operatorname{Int} 1_{\mathrm{mal}}\right]$



where $\mathrm{F}_{\mathrm{Asn}}$ is the fraction of asparagine that is converted to acrylamide. Note that during the reactions associated with $\mathrm{k}_{1}$ and $\mathrm{k}_{1 \mathrm{mal}}$, the free amino acids are regenerated so there is no loss of free amino acids associated with these pathways.

291 Athena Visual Studio was used to solve the simultaneous differential equations and estimate the 292 parameters using the data from the maltose-dipped fries, combined with the data from the fries with 293 variable glucose and fructose content taken from Parker et al. (2012). The parameter estimates are 294 shown in Figure 2. Overall, the parameters were good with respect to their $95 \%$ confidence 
intervals. The fit of the model to the experimental values is very good, and for the maltose-dipped samples this is demonstrated in Figure 1. The overall quality of the fit is shown in Figure 3, where

297 the observed vs. predicted plots include all the measured responses from all available datasets. In all cases linear regression gave slopes close to 1.0 (0.96 to 0.103$)$ and generally the $R^{2}$ was $>0.95$. The exceptions were for the free amino acids where there was more scatter, but the slope was still 1.0. The estimate for parameter $\mathrm{F}_{\text {Asn }}$ is $32 \times 10^{-4}$, which implies that $0.3 \%$ of the asparagine is converted to acrylamide. Also, parameter $p$ was estimated as 0.85 , which implies that from 1 mole of intermediates with an intact sugar backbone, 1.85 moles of fragmentation products are formed. Comparison of the kinetics of the formation of acrylamide from the three sugars was carried out in Athena using model simulations. Using the rate constants from Figure 2, the model was run at 165 ${ }^{\circ} \mathrm{C}$ where the concentration of the total FAA and Asn were set to 164 and $60 \mathrm{mmol} / \mathrm{kg}$ dry weight respectively (the same as in M0), and the initial acrylamide (generated during par-frying) was set to zero. In turn, each of the sugars was set to $40 \mathrm{mmol} / \mathrm{kg}$ dry weight (falling within the experimental ranges used) whilst the other two were set to zero, in order to determine the individual contribution from each of the sugars. The simulations are shown in Figure 4a, and it is clear that maltose makes only a small contribution to the total acrylamide formation. Figure $4 \mathrm{~b}$ shows the data as a $\%$ of total,

311 where it is clear that fructose is initially faster than glucose under these particular conditions, and 312 the contribution from maltose increases with frying time to a maximum of $10 \%$ of the total.

313 However for the first 200 seconds, the contribution from maltose is less than $5 \%$.

\subsection{Incorporation of specific and generic pathways into the kinetic model}

315 During food processing, two related pathways have been proposed for acrylamide formation (Parker 316 et al., 2012): the "specific amino acid pathway" and the "generic amino acid pathway". Whereas

317 Kinetic Mechanism 1 provides a very good model to describe the formation of acrylamide during 318 frying, it does not discriminate between the generic and the specific amino acid pathways.

319 The generic amino acid pathway involves the Maillard reaction (top line, Figure 5) - the reaction 320 between any of the free amino acids present in the food with reducing sugars to form a series of 
321 Schiff bases. These rearrange to form the corresponding Amadori rearrangement products, and the 322 subsequent cascade of reactions results in the formation of highly reactive deoxyosones and short 323 chain carbonyl intermediates, particularly $\alpha$-dicarbonyls such as glyoxal and methylglyoxal, $\alpha$ 324 hydroxycarbonyls such as glycolaldehyde and hydroxypropanone, and also trioses and tetroses. 325 Many of these carbonyls react with amino acids more effectively than glucose does (Hofmann, 326 1999) and in particular with free asparagine to form acrylamide. This could be via the $\alpha$ 327 hydroxycarbonyls as detailed by Stadler, Robert, Riediker, Varga, Davidek, Devaud et al. (2004) 328 (centre of Figure 5), or via $\alpha$-dicarbonyls as shown by Koutsidis et al. (2008) and Amrein, 329 Limacher, Conde-Petit, Amado, \& Escher (2006) (right-hand side of Figure 5). The chemistry of 330 this latter pathway has been less well defined but is certainly different when there is a vicinal 331 dicarbonyl involved. It may proceed via the 3-aminopropionamide, returning a dicarbonyl, or via $\beta$ 332 elimination (Stadler et al., 2004). In both cases, whether the reactive species is a dicarbonyl or a 333 hydroxycarbonyl, the Maillard reaction provides a source of those particularly reactive species that 334 asparagine requires in order to induce acrylamide formation. These pathways are certainly Maillard 335 assisted.

336 During the specific amino acid pathway, asparagine reacts directly with the reducing sugars present 337 in the food to form a sugar-asparagine glycoconjugate which dehydrates to a Schiff base (left-hand 338 side of Figure 5). This is followed by a series of reactions which involve the decarboxylation of the 339 Schiff base (thus by-passing the formation of the Amadori rearrangement product), and a 340 subsequent tautomerism which leads to the formation of acrylamide (Stadler et al., 2004). The 341 chemical mechanism involved in this pathway is the same as for the Maillard assisted pathway via 342 hydroxycarbonyls (Figure 5). However, the kinetics of this pathway are different, because it does 343 not require the initial formation of a source of reactive carbonyls. For the remainder of the kinetic 344 discussion, we will refer to this pathway as the specific sugar-Asn pathway.

345 It is important at this stage to highlight the difference between a chemical mechanism and a kinetic 346 mechanism. Chemically, what we have referred to previously as the specific amino acid mechanism 
347 includes the reaction of asparagine directly with C6 reducing sugars and other $\alpha$-hydroxycarbonyls

348 which are formed during the Maillard reaction (Stadler et al., 2004). However kinetically, the

349 specific reaction with Maillard-derived $\alpha$-hydroxycarbonyls is effectively initiated by any amino

350 acid, and is therefore indistinguishable, from a kinetic point of view, from the generic amino acid

351 pathway. This Maillard-assisted specific amino acid pathway follows the chemistry of the specific

352 sugar-Asn pathway, but the kinetics of the general pathway.

353 Although the generic amino acid pathway involves several more steps, the reaction of asparagine

354 with the highly reactive carbonyl intermediates may be faster than the first step of the specific

355 sugar-Asn pathway. The proportion that each of these pathways contributes to the formation of

356 acrylamide in food is not yet clear, and is likely to depend on the composition of the raw material,

357 as discussed by Ngyuen et al. (2016).

358 Taking this into consideration, a new kinetic mechanism was proposed (Kinetic Mechanism 2,

359 Figure 1). The right-hand side of the mechanism expresses the specific sugar-Asn pathway, where

360 each sugar reacts with asparagine, and acrylamide is formed via a single kinetically important step.

361 The left-hand side of the mechanism expresses the generic amino acid pathway where acrylamide is

362 formed from the reaction of asparagine with a group of very reactive intermediates $\mathrm{Int}_{2}$, as was

363 described in detail previously in this paper. Note that this also includes the reaction of reactive

364 hydroxycarbonyls via the Stadler chemical mechanism. The differential equations derived from

365 Kinetic Mechanism 2 (Model 2) are:

366

$\frac{\mathrm{d}[\mathrm{Glu}]}{\mathrm{dt}}=-\mathrm{k}_{1}[\mathrm{Glu}][\mathrm{FAA}]+\mathrm{k}_{2 \mathrm{mal}}\left[\mathrm{Int} 1_{\mathrm{mal}}\right]-\mathrm{k}_{8}[\mathrm{Glu}]-\mathrm{k}_{\mathrm{g}}[\mathrm{Glu}][\mathrm{Asn}]$

$\frac{\mathrm{d}[\mathrm{Fru}]}{\mathrm{dt}}=-\mathrm{k}_{6}[\mathrm{Fru}]+\mathrm{k}_{8}[\mathrm{Glu}]-\mathrm{k}_{\mathrm{f}}[$ Fru $][$ Asn $]$

368

$\frac{\mathrm{d}[\mathrm{Mal}]}{\mathrm{dt}}=-\mathrm{k}_{1 \mathrm{mal}}[\mathrm{Mal}][\mathrm{FAA}]-\mathrm{k}_{\mathrm{m}}[\mathrm{Mal}][\mathrm{Asn}]$

$\frac{\mathrm{d}[\text { FAAs }]}{\mathrm{dt}}=-\mathrm{k}_{3}[$ Int2][FAA $]-\mathrm{k}_{\mathrm{g}}[$ Glu $][$ Asn $]-\mathrm{k}_{\mathrm{f}}[$ Fru $][$ Asn $]-\mathrm{k}_{\mathrm{m}}[$ Mal] $[$ Asn $]$

$\frac{\mathrm{d}[\text { Asn }]}{\mathrm{dt}}=-\mathrm{k}_{3}[$ Int2][Asn $]-\mathrm{k}_{\mathrm{g}}[$ Glu $][$ Asn $]-\mathrm{k}_{\mathrm{f}}[\mathrm{Fru}][$ Asn $]-\mathrm{k}_{\mathrm{m}}[$ Mal $][$ Asn $]$ 
$\frac{\mathrm{d}[\text { Acr }]}{\mathrm{dt}}=\mathrm{k}_{3}[$ Int2][Asn $] * \mathrm{~F}_{\text {Asn }}+\mathrm{k}_{\mathrm{g}}[$ Glu $][$ Asn $]+\mathrm{k}_{\mathrm{f}}[$ Fru $][$ Asn $]+\mathrm{k}_{\mathrm{m}}[$ Mal $][$ Asn $]$

$\frac{\mathrm{d}\left[\operatorname{Int} 1_{\mathrm{mal}}\right]}{\mathrm{dt}}=\mathrm{k}_{1 \mathrm{mal}}[\mathrm{Mal}][\mathrm{FAA}]-\mathrm{k}_{2 \mathrm{mal}}\left[\operatorname{Int} 1_{\mathrm{mal}}\right]$

$\frac{\mathrm{d}[\operatorname{Int} 2]}{\mathrm{dt}}=(1+\mathrm{p})\left(\mathrm{k}_{1}[\mathrm{Glu}][\mathrm{FAA}]+\mathrm{k}_{6}[\mathrm{Fru}]+\mathrm{k}_{2 \mathrm{mal}}\left[\operatorname{Int} 1_{\mathrm{mal}}\right]\right)-\mathrm{k}_{3}[\operatorname{Int} 2][\mathrm{FAA}]$

This model contains three more parameters than the model 1. Athena Visual Studio was used to solve the simultaneous differential equations and estimate the parameters. As for Model 1, the combined data were used for parameter estimation giving rise to Model 2. The estimated parameters of Model 2, as calculated by Athena Visual Studio, are shown in Figure 2. The fit of the model to the experimental data is very good and similar to the fit of the model of Kinetic Mechanism 1. The fits are shown in supplementary figures S2 and S3. Similar to Model 1, parameter $p$ was estimated as 0.66 , which implies that from 1 mole of intermediates with an intact sugar backbone, 1.66 moles of fragmentation products are formed. All the estimates for the reaction rate constants of Kinetic Mechanism 2 were estimated with acceptable 95\% confidence intervals (Figure 2) with the exception of $\mathrm{k}_{\mathrm{m}}$ which was returned as lower bound (zero). This shows that both generic and specific sugar-Asn pathways are likely to contribute to the formation of acrylamide in french fries and model simulations suggest that there is a significant contribution from both. Acrylamide is formed via both routes when the participating sugars are glucose and fructose, but the formation from maltose via the maltose glycoconjugate is kinetically insignificant and maltose contributes to the generation of acrylamide only via the generic amino acid pathway or via glucose.

\subsection{Discussion of the chemical mechanisms}

We can draw some significant conclusions from the kinetic modelling. The data obtained could not

391 be fitted to the specific sugar-Asn route, but good models were obtained when the model was based on the generic amino acid pathway (Model 1) and when we allowed the model to incorporate the specific sugar-Asn route as well (Model 2). Although in modelling terms, Model 1 is preferable because it is simpler, Model 2 shows that both routes are likely to contribute. To our knowledge, 
specific sugar-Asn and the generic amino acid pathways. Early models tended to favour the specific sugar-Asn pathway as proposed by Stadler et al. (2004), and confirmed by Zyzak et al. (2003) who

398 showed evidence of the intermediate decarboxylated Amadori product in a high sugar system. Knoll and coworkers modelled their data from aqueous buffered asparagine/glucose (Knol et al., 2005) or asparagine/fructose (Knol et al., 2010) model systems using a two-step reaction based on the specific amino acid pathway. This was successfully extended into low moisture systems by De

Vleeschouwer and co-workers (2008b, 2009b) who found that the best kinetic model fitted the specific sugar-Asn pathway for acrylamide formation, and also included the Maillard reaction as a browning pathway, but not as a source of reactive intermediates for acrylamide formation. This fit is not unexpected from a system that contains just one amino acid and no other source of reactive carbonyl species. However, this model also fitted when the data were collected from a potato-based matrix (De Vleeschouwer et al., 2008a). Van der Fels-Klerx and co-workers (Nguyen et al., 2016, 408 2017) considered both the generic and specific sugar-Asn pathways when they developed their 409 model for acrylamide formation in biscuits, and again found the better models involved just asparagine, although in their latest model, (Van Der Fels-Klerx et al., 2014) which incorporated the 411 participation of other free amino acids, the best model included the Maillard reaction as a sink for 412 the excess sugars, but not as a source of reactive intermediates for acrylamide formation. Wedzicha 413 et al. (2005) and Low, Mottram, \& Elmore (2006) proposed a general amino acid pathway for the 414 formation of acrylamide and developed a kinetic model for the formation of acrylamide in low 415 sugar systems (potato, rye and wheat products). They observed the competition between the 416 formation of acrylamide and other Maillard-derived compounds, from a common pool of 417 intermediates, providing evidence for a significant contribution from the generic amino acid 418 pathway. In our earlier work (Parker et al., 2012), we initially considered both specific and general 419 amino acid pathways, but the model with the best fit was based on a three-step reaction relying on 420 the Maillard reaction to generate highly reactive intermediates (generic amino acid pathway) and 421 there were insufficient data to split the model into a generic and a specific component. In summary, 
there is good evidence for both the existence of the specific sugar-Asn pathway in model systems and biscuits, and the existence of the general amino acid pathway in cereals and potatoes. In this paper, we have shown that these routes can co-exist during the frying of potato fries, and it is likely that the contribution from the Maillard reaction depends certainly on the composition of the food, and possibly on other factors. At one extreme, the glucose/asparagine model systems of Knoll and co-workers $(2010,2005)$ were dominated by the specific pathway, since none of the particularly reactive amino acids was present to promote the Maillard reaction and the formation of reactive carbonyls. In the high sugar biscuit models (Nguyen et al., 2016, 2017) the molar ratio of reducing sugars to asparagine was high ( 50:1), and the contribution from the Maillard-assisted route may be small enough that the best fit model is still based on the specific sugar-Asn pathway. However in french fries, the molar ratio of reducing sugars to asparagine was low $(\sim 1: 10)$, and model 2 suggests a much greater contribution from the Maillard reaction. Under these conditions, the formation of acrylamide is "Maillard assisted" by the accumulation of reactive carbonyl intermediates. This is an important point to emphasise - the fact that the chemical mechanisms can change depending on the composition of the food.

\section{Conclusion}

This is the first time that a holistic and robust model of acrylamide formation has been developed in a real and complex food incorporating glucose, fructose and maltose, as well as moisture and heat transfer parameters, and giving some insight into the relative contribution from different formation pathways. At equimolar concentrations, maltose contributed $<10 \%$ to the total acrylamide formation, giving us less concern over acrylamide levels in foods containing or generating maltose (and by extension, higher oligomers of glucose). The first model demonstrates that the breakdown of maltose and subsequent formation of acrylamide is relatively slow, whether this be via a maltose Maillard intermediate route or via the "peel off" of glucose. The pathways from maltose require three rate limiting steps as opposed to two from glucose or fructose. Model 2 which allowed for the formation of acrylamide directly from sugar-asparagine glycoconjugates, showed there was a 
448 contribution from the glucose and fructose glycoconjugates, but not from maltose glycoconjugate.

449 The more we understand about the formation pathways of acrylamide in real food systems, the

450 better we are equipped to develop appropriate mitigation strategies.

451 Supporting information

452 Figure S1. Graphs showing fit of all experimental data to model 1, generated from Kinetic

453 Mechanism 1.

454 Figure S2. Graphs showing fit of all experimental data to model 2, generated from Kinetic

455 Mechanism 2.

456 Figure S2. Graphs showing predicted vs. observed values for model 2, generated from Kinetic 457 Mechanism 2. 


\section{References}

Aguilera, J. M., \& Gloria-Hernandez, H. (2000). Oil absorption during frying of frozen parfried potatoes. J. Food Sci., 65(3), 476-479.

Amrein, T. M., Limacher, A., Conde-Petit, B., Amado, R., \& Escher, F. (2006). Influence of thermal processing conditions on acrylamide generation and browning in a potato model system. J. Agric. Food Chem., 54, 5910-5916.

Balagiannis, D. (2014). Predicting aroma formation with kinetic models. In J. K. Parker, J. S. Elmore \& L. Methven (Eds.), Flavour Development, Analysis and Perception in Food and Beverages, (pp. 211-233). Cambridge, UK: Woodhead Publishing.

Balagiannis, D. P., Parker, J. K., Higley, J., Henson, T., Smith, G., Wedzicha, B. L., \& Mottram, D. S. (2016). A three dimensional kinetic model for the formation of acrylamide in french fries with variable glucose and fructose content. In M. Granvogl, P. Schieberle \& D. Peterson (Eds.), Browned Flavors: Analysis, Formation, \& Physiology, (pp. 67). Washington DC: ACS.

Balagiannis, D. P., Parker, J. K., Pyle, D. L., Desforges, N., Wedzicha, B. L., \& Mottram, D. S. (2009). Kinetic modeling of the generation of 2- and 3-methylbutanal in a heated extract of beef liver. J. Agric. Food Chem., 57, 9916-9922.

Brands, C. M. J., \& van Boekel, M. A. J. S. (2002). Kinetic modeling of reactions in heated monosaccharide-casein systems. J. Agric. Food Chem., 50, 6725-6739.

Commision Regulation (EU) 2017/2158 of November 2017, Establishing mitigation measures and benchmark levels for the reduction of the presence of acrylamide in food. Official Journal of the European Union L304/24.

De Vleeschouwer, K., Van der Plancken, I., Van Loey, A., \& Hendrickx, M. E. (2008a). Investigation of the influence of different moisture levels on acrylamide formation/elimination reactions using multiresponse analysis. J. Agric. Food Chem., 56(15), 6460-6470. 
De Vleeschouwer, K., Van der Plancken, I., van Loey, A., \& Hendrickx, M. E. (2008b). The kinetics of acrylamide formation/elimination in asparagine-glucose systems at different initial reactant concentrations and ratios. Food Chem., 111, 719-729.

De Vleeschouwer, K., Van der Plancken, I., Van Loey, A., \& Hendrickx, M. E. (2009a). Modelling acrylamide changes in foods: from single-response empirical to multiresponse mechanistic approaches. Trends Food Sci. Technol., 20, 155-167.

De Vleeschouwer, K., Van der Plancken, I., Van Loey, A., \& Hendrickx, M. E. (2009b). Role of precursors on the kinetics of acrylamide formation and elimination under low moisture conditions using a multiresponse approach - Part II: Competitive reactions. Food Chem., $114,535-546$.

Frank, O., \& Hofmann, T. (2000). On the influence of the carbohydrate moiety on chromophore formation during food-related Maillard reactions of pentoses, hexoses, and disaccharides. Helv. Chim. Acta, 83, 3246-3261.

Halford, N. G., Curtis, T. Y., Muttucumaru, N., Postles, J., Elmore, J. S., \& Mottram, D. S. (2012). The acrylamide problem: a plant and agronomic science issue. J. Exp. Bot., 63(8), 28412851.

Hofmann, T. (1999). Quantitative studies on the role of browning precursors in the Maillard reaction of pentoses and hexoses with L-alanine. Eur. Food Res. Technol., 209, 113-121.

Hollnagel, A., \& Kroh, L. W. (2000). Degradation of oligosaccharides in nonenzymatic browning by formation of $\alpha$-dicarbonyl compounds via a "peeling off" mechanism. J. Agric. Food Chem., 48, 6219-6226.

IARC (1994). International Agency for Research on Cancer. IARC Monographs on the Evaluation of Carcinogenic Risks to Humans. 60, 389-433.

Knol, J. J., Linssen, J. P. H., \& van Boekel, M. A. J. S. (2010). Unravelling the kinetics of the formation of acrylamide in the Maillard reaction of fructose and asparagine by multiresponse modelling. Food Chem., 120, 1047-1057. 
Knol, J. J., van Loon, W. A. M., Linssen, J. P. H., Ruck, A.-L., van Boekel, M. A. J. S., \& Voragen, A. G. J. (2005). Toward a kinetic model for acrylamide formation in a glucose-asparagine reaction system. J. Agric. Food Chem., 53, 6133-6139.

Koutsidis, G., De la Fuente, A., Dimitriou, C., Kakoulli, A., Wedzicha, B. L., \& Mottram, D. S. (2008). Acrylamide and pyrazine formation in model systems containing asparagine. J. Ag. Food Chem., 56(15), 6105-6112.

Kramhoeller, B., Pischetsrieder, M., \& Severin, T. (1993). Maillard reactions of lactose and maltose. J. Agric. Food Chem., 41(3), 347-351.

Lingnert, H. (1990). Development of the Maillard reaction during food processing. In P. A. Finot, H. U. Aeschbacher, R. F. Hurrel \& R. Liardon (Eds.), The Maillard Reaction in Food Processing, Human Nutrition and Physiology, (pp. 171-186). Basel: Birkhauser.

Low, M. Y. (2006). Relationship between acrylamide formation and flavour generation in heated foods. Unpublished PhD Thesis, University of Reading, Reading, UK.

Low, M. Y., Mottram, D. S., \& Elmore, J. S. (2006). Relationship between acrylamide formation and the generation of flavour in heated foods. Dev. Food Sci.,43, 363-366.

Martins, S. I. F. S., \& van Boekel, M. A. J. S. (2004). A kinetic model for the glucose/glycine Maillard reaction pathways. Food Chem. , 257-269.

Mundt, S., \& Wedzicha, B. L. (2005). Role of glucose in the Maillard browning of maltose and glycine: A radiochemical approach. J. Agric. Food Chem., 53, 6798-6803.

Nguyen, H. T., Van der Fels-Klerx, H. J., Peters, R. J. B., \& van Boekel, M. A. J. S. (2016). Acrylamide and 5-hydroxymethylfurfural formation during baking of biscuits: Part I: Effects of sugar type. Food Chem., 192, 575-585.

Nguyen, H. T., Van der Fels-Klerx, H. J., \& van Boekel, M. A. J. S. (2017). Acrylamide and 5hydroxymethylfurfural formation during biscuit baking. Part II: Effect of the ratio of reducing sugars and asparagine. Food Chem., 230, 14-23. 
Ni, H., \& Datta, A. K. (1999). Moisture, oil and energy transport during deep-fat frying of food materials. Food and Bioproducts Processing, 77(3), 194-204.

Nursten, H. (2005). The Maillard Reaction: Chemistry, Biochemistry and Implications. Cambridge: Royal Society of Chemistry.

Parker, J. K. (2013). The kinetics of thermal generation of flavour. J. Sci. Food Agric., 93(2), 197208.

Parker, J. K., Balagiannis, D. P., Higley, J., Smith, G., Wedzicha, B. L., \& Mottram, D. S. (2012). Kinetic model for the formation of acrylamide during the finish-frying of commercial French fries. J. Agric. Food Chem., 60(36), 9321-9331.

Pischetsrieder, M. and Severin, T. (1996) Advanced Maillard reaction products of disaccharides: analysis and relation to reaction conditions. In T.C. Lee \& H,J, Kim (Eds.), Chemical Markers for Processed and Stored Foods, (pp 14-23). Washington DC: ACS.

Smuda, M. \& Glomb, M.A. (2011). Novel insights into the Maillard catalyzed degradation of maltose. J. Agric. Food Chem., 59, 13254-13264.

Stadler, R. H., Robert, F., Riediker, S., Varga, N., Davidek, T., Devaud, S., Goldmann, T., Hau, J., \& Blank, I. (2004). In-depth mechanistic study on the formation of acrylamide and other vinylogous compounds by the Maillard reaction. J. Agric. Food Chem., 52(17), 5550-5558.

Takahata, Y., Noda, T., \& Nagata, T. (1994). Effect of $\beta$-amylase stability and starch gelatinization during heating on varietal differences in maltose content in sweetpotatoes. J. Agric. Food Chem., 42, 2564-2569.

van Boekel, M. A. J. S. (2008). Multiresponse kinetic modeling of chemical reactions. In Kinetic Modeling of Reactions In Foods. Boca Raton, FL,: CRC Press.

Van Der Fels-Klerx, H. J., Capuano, E., Nguyen, H. T., Atac Mogol, B., Kocadağli, T., Göncüoğlu Taş, N., Hamzalioğlu, A., van Boekel, M. A. J. S., \& Gökmen, V. (2014). Acrylamide and 5-hydroxymethylfurfural formation during baking of biscuits: $\mathrm{NaCl}$ and temperature-time profile effects and kinetics. Food Res. Int., 57, 210-217. 
561 Wedzicha, B. L., \& Kedward, C. (1995). Kinetics of the oligosaccharide-glycine-sulfite reaction: relationship to the browning of oligosaccharide mixtures. Food Chem., 54, 397-402.

563 Wedzicha, B. L., Mottram, D. S., Elmore, J. S., Koutsidis, G., \& Dodson, A. T. (2005b). Kinetic 564 models as a route to control acrylamide formation in food. Adv. Exp. Med. Biol., 565 561(Chemistry and Safety of Acrylamide in Food), 235-253.

566 Zyzak, D. V., Sanders, R. A., Stojanovic, M., Tallmadge, D. H., Eberhart, B. L., Ewald, D. K., 567 Gruber, D. C., Morsch, T. R., Strothers, M. A., Rizzi, G. P., \& Villagran, M. D. (2003).

568 Acrylamide formation mechanism in heated foods. J. Agric. Food Chem., 51, 4782-4787. 
Table 1. Comparison of the rate of change of maltose and acrylamide in the maltose-dipped french fries and the $2 \%$ glucose-or fructose-dipped fries (data taken from Parker et al. (2012)) after finish frying at $165^{\circ} \mathrm{C}$ for $5 \mathrm{~min}$.

\begin{tabular}{|c|c|c|c|c|c|c|c|c|}
\hline \multirow[b]{2}{*}{ Addition level } & \multicolumn{6}{|c|}{ Maltose } & \multirow{2}{*}{$\begin{array}{c}\text { Glucose } \\
2 \%\end{array}$} & \multirow{2}{*}{$\begin{array}{c}\text { Fructose } \\
2 \%\end{array}$} \\
\hline & $0 \%$ & $1 \%$ & $2 \%$ & $3 \%$ & $4 \%$ & $14 \%$ & & \\
\hline Sug $_{\text {ini }}{ }^{2}$ & - & 16.4 & 24.2 & 41.6 & 47.3 & 164 & 63.0 & 72.8 \\
\hline Sug $_{\text {fin }}$ b & - & 7.1 & 13.5 & 20.7 & 26.3 & 111 & 27.3 & 50.4 \\
\hline Sug $_{\text {ini-Sug }}$ fin $^{c}$ & - & 9.2 & 10.7 & 20.9 & 21.0 & 52.4 & 35.8 & 22.4 \\
\hline $\operatorname{Acr}_{\text {fin }}-$ Acrini $^{d}$ & 4.5 & 10.9 & 20.1 & 17.5 & 19.4 & 20.8 & 72.7 & 75.4 \\
\hline Colour (Agtron Score) ${ }^{\mathrm{e}}$ & 70.8 & 63.2 & 56.1 & 52.9 & 53.4 & 34.6 & 26.3 & 34.8 \\
\hline
\end{tabular}

${ }^{\mathrm{a}}$ concentration of the added sugar in fries before finish-frying (mmol/kg dry weight), ${ }^{b}$ concentration of the added sugar in fries after finish-frying (mmol/kg dry weight), ${ }^{\mathrm{c}}$ loss of added sugar (mmol/kg dry weight) during finish frying, ${ }^{\mathrm{d}}$ concentration of acrylamide in fries after finish frying ( $\mu \mathrm{mol} / \mathrm{kg}$ dry weight), ${ }^{\mathrm{e}}$ colour after finish frying 

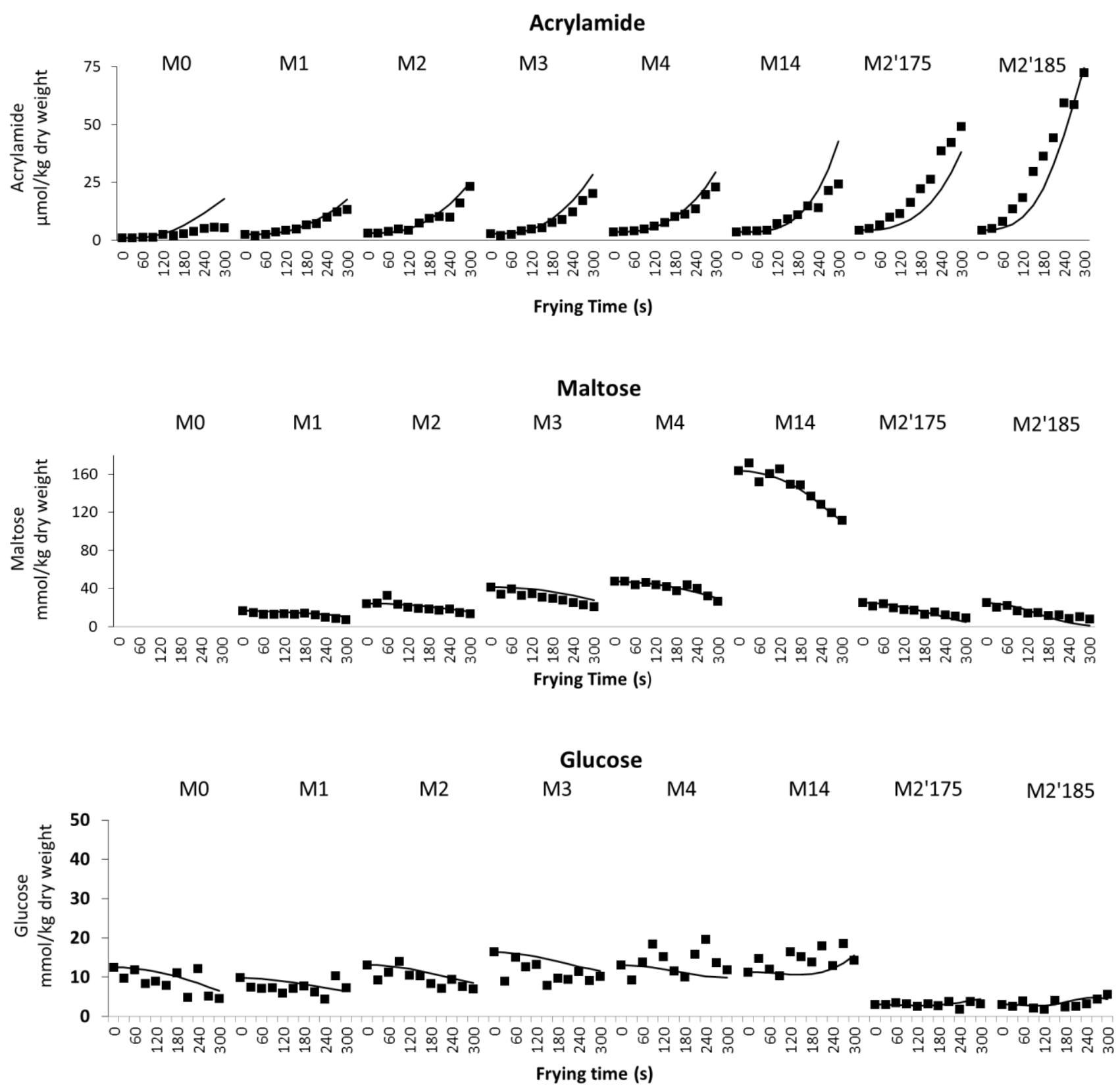

Figure 1. Acrylamide, maltose and glucose concentrations as a function of time $(0-300 \mathrm{~s})$ during finish-frying of eight batches of maltose-dipped potato strips at $165{ }^{\circ} \mathrm{C}(\mathrm{M} 0, \mathrm{M} 1, \mathrm{M} 2$, M3, M4 and M14 represent $0,1,2,3,4$ and 14\% dip respectively), $175^{\circ} \mathrm{C}\left(\mathrm{M} 2{ }^{\prime} 175=2 \%\right.$ dip) and $185^{\circ} \mathrm{C}\left(\mathrm{M} 2{ }^{\prime} 185=2 \%\right.$ dip ). Symbols (匹) are the experimental data points and the line (-) shows kinetic Model 1 derived from the combined data set using Kinetic Mechanism 1 (Figure 2). 


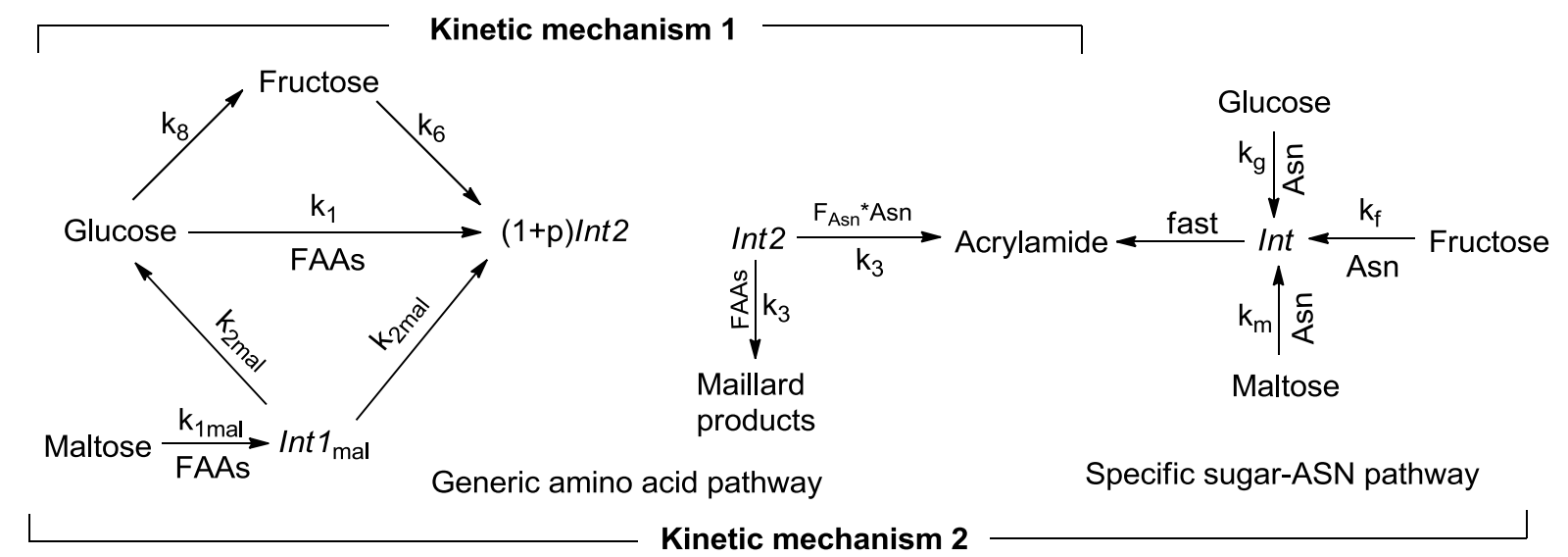

\begin{tabular}{|c|c|c|c|c|}
\hline \multirow[t]{2}{*}{ Parameter } & \multicolumn{2}{|c|}{$\begin{array}{c}\text { Model } 1 \text { based on } \\
\text { Kinetic Mechanism } 1\end{array}$} & \multicolumn{2}{|c|}{$\begin{array}{c}\text { Model } 2 \text { based on } \\
\text { Kinetic Mechanism } 2\end{array}$} \\
\hline & $\begin{array}{c}\text { Optimal estimate } \\
\times 10^{4}\end{array}$ & $\begin{array}{l}95 \% \text { Confidence } \\
\text { interval } \times 10^{4}\end{array}$ & $\begin{array}{l}\text { Optimal estimate } \\
\times 10^{4}\end{array}$ & $\begin{array}{c}95 \% \text { Confidence } \\
\text { interval x } 10^{4}\end{array}$ \\
\hline $\mathrm{k}_{1}\left(\mathrm{mmol}^{-1} \mathrm{~kg} \mathrm{~s}^{-1}\right)$ & 2.2 & $\pm 0.03(1 \%)$ & 2.1 & $\pm 0.3(16 \%)$ \\
\hline $\mathrm{k}_{3}\left(\mathrm{mmol}^{-1} \mathrm{~kg} \mathrm{~s}^{-1}\right)$ & 72 & $\pm 25(35 \%)$ & 220 & $\pm 62(28 \%)$ \\
\hline $\mathrm{k}_{6}\left(\mathrm{~S}^{-1}\right)$ & 165 & $\pm 9(5 \%)$ & 161 & $\pm 13(8 \%)$ \\
\hline $\mathrm{k}_{8}\left(\mathrm{~s}^{-1}\right)$ & 68 & $\pm 8(12 \%)$ & 73 & $\pm 15(20 \%)$ \\
\hline$p$ & 8550 & $\pm 2510(29 \%)$ & 6640 & $\pm 2713(41 \%)$ \\
\hline $\mathrm{F}_{\text {Asn }}$ & 32 & $\pm 4(14 \%)$ & 18 & $\pm 7(38 \%)$ \\
\hline $\mathrm{k}_{1 \mathrm{mal}}\left(\mathrm{mmol}^{-1} \mathrm{~kg} \mathrm{~s}^{-1}\right)$ & 2.3 & $\pm 0.1(5 \%)$ & 2.3 & $\pm 0.1(5 \%)$ \\
\hline $\mathrm{k}_{2 \mathrm{mal}}\left(\mathrm{s}^{-1}\right)$ & 162 & $\pm 25(15 \%)$ & 245 & $\pm 60(25 \%)$ \\
\hline $\mathrm{kg}\left(\mathrm{mmol}^{-1} \mathrm{~kg} \mathrm{~s}^{-1}\right)$ & & & 0.006 & $\pm 0.003(45 \%)$ \\
\hline $\mathrm{k}_{\mathrm{f}}\left(\mathrm{mmol}^{-1} \mathrm{~kg} \mathrm{~s}^{-1}\right)$ & & & 0.005 & $\pm 0.002(40 \%)$ \\
\hline $\mathrm{km}_{\mathrm{m}}\left(\mathrm{mmol}^{-1} \mathrm{~kg} \mathrm{~s}^{-1}\right)$ & & & 0 (lower bound) & - \\
\hline
\end{tabular}

Figure 2. Postulated Kinetic Mechanisms 1 and 2 with parameter estimates for Model 1 and Model 2 respectively, generated from data from fructose-, glucose- and maltose-dipped potato strips. The rate constants correspond to a temperature of $165^{\circ} \mathrm{C}$. 

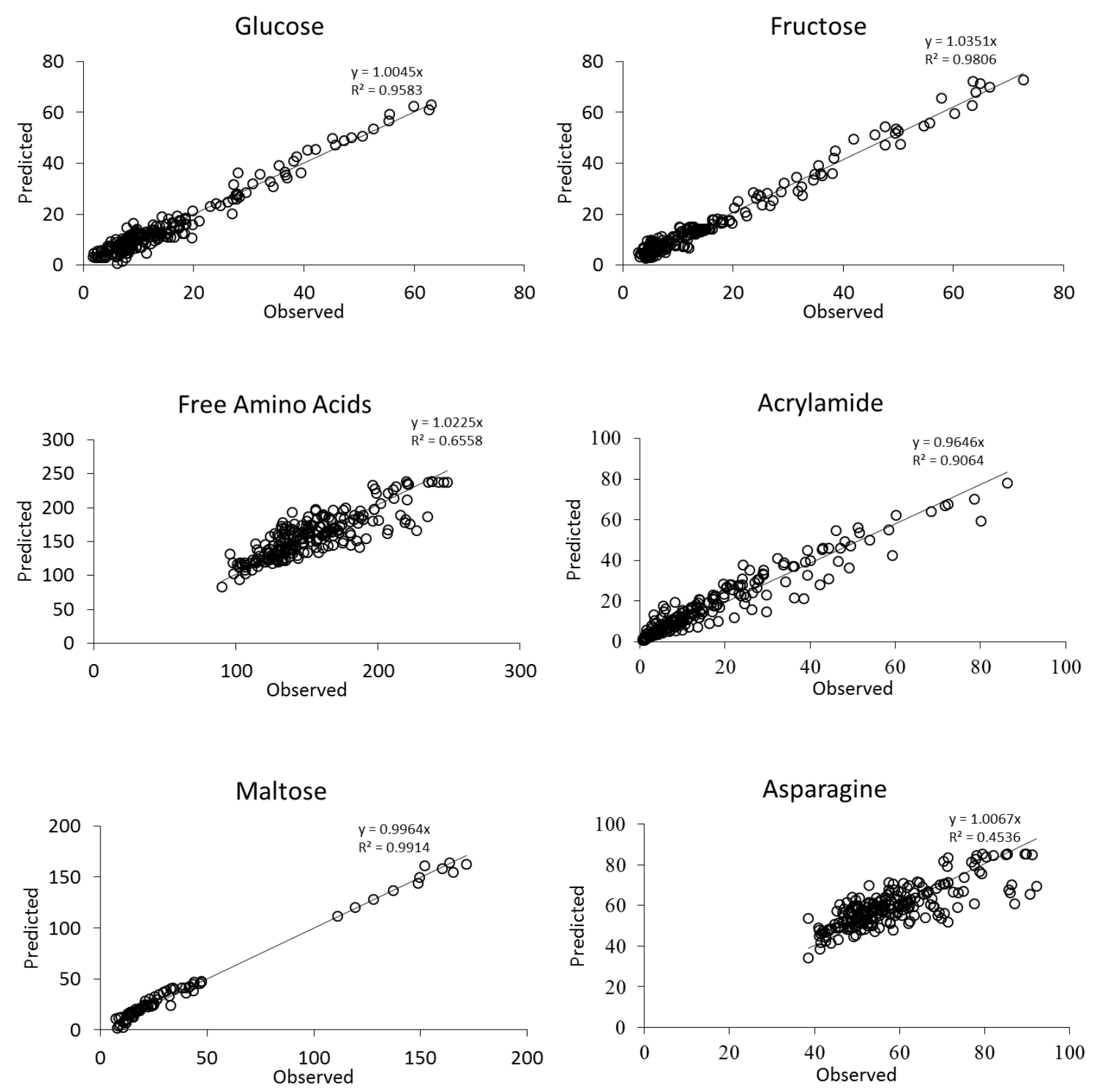

Figure 3. Predicted against observed values for Model 1 for all batches of fries compared with the line of perfect fit $(\mathrm{y}=1)$. In all graphs the units are $\mathrm{mmol} / \mathrm{kg}$ fat-free dry weight, except acrylamide which is expressed as $\mu \mathrm{mol} / \mathrm{kg}$ fat-free dry weight. Linear regression was performed on each dataset to produce a slope (y) and $\mathrm{R}^{2}$. 

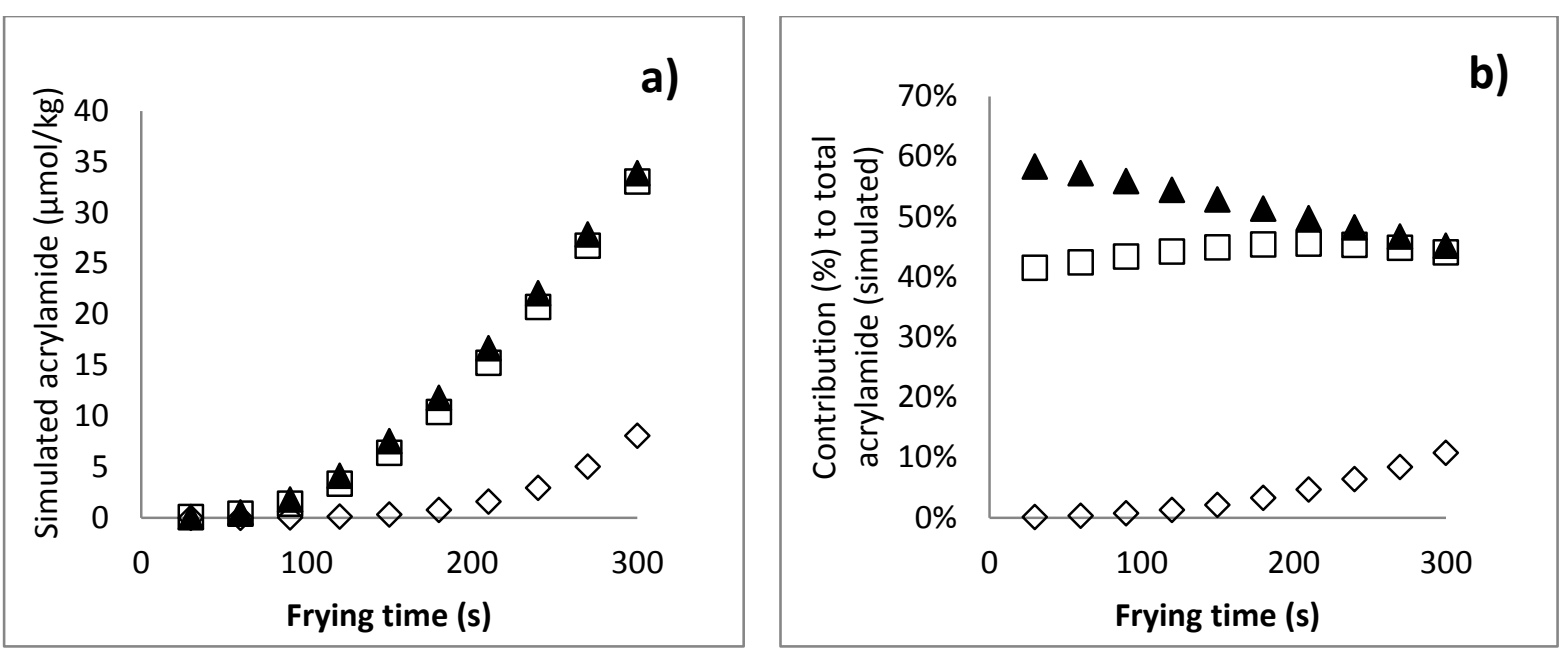

Figure 4. For Kinetic Mechanism 1, comparison of (a) the concentration of acrylamide formed and b) the $\%$ contribution to total acrylamide from glucose $(\square)$, fructose ( $\boldsymbol{\Delta})$, and maltose $(\diamond)$ using model simulations at $165^{\circ} \mathrm{C}$ where $[\mathrm{FAA}]$ at $\mathrm{t}=0$ was set to $146 \mathrm{mmol} / \mathrm{kg}$ dry weight, [Asn] to $60 \mathrm{mmol} / \mathrm{kg}$ dry weight, and the sugars were each set at $40 \mathrm{mmol} / \mathrm{kg}$ dry weight whilst the other two were set at 0 . 


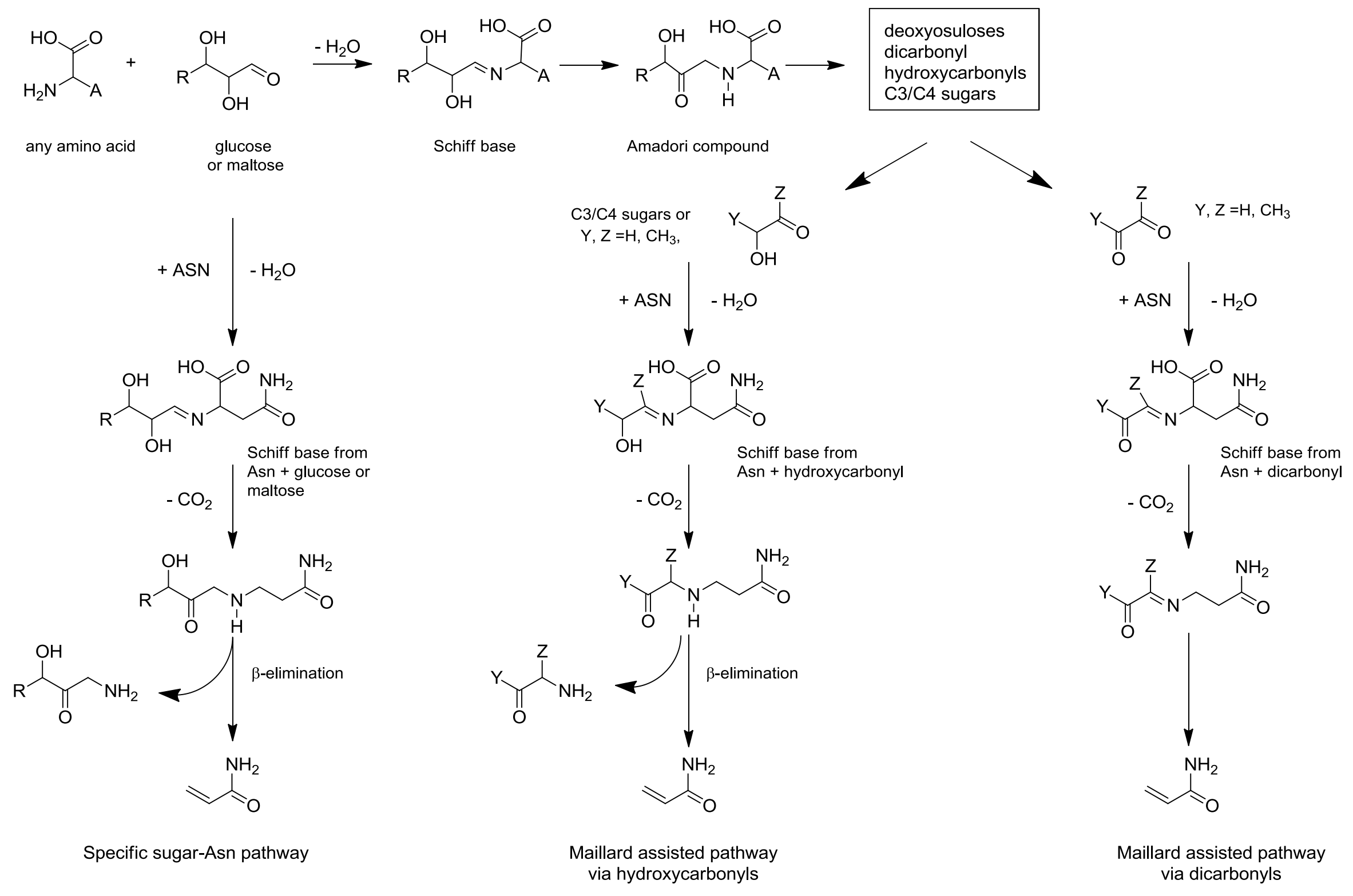

Figure 5. Proposed chemical mechanisms for the formation of acrylamide. 


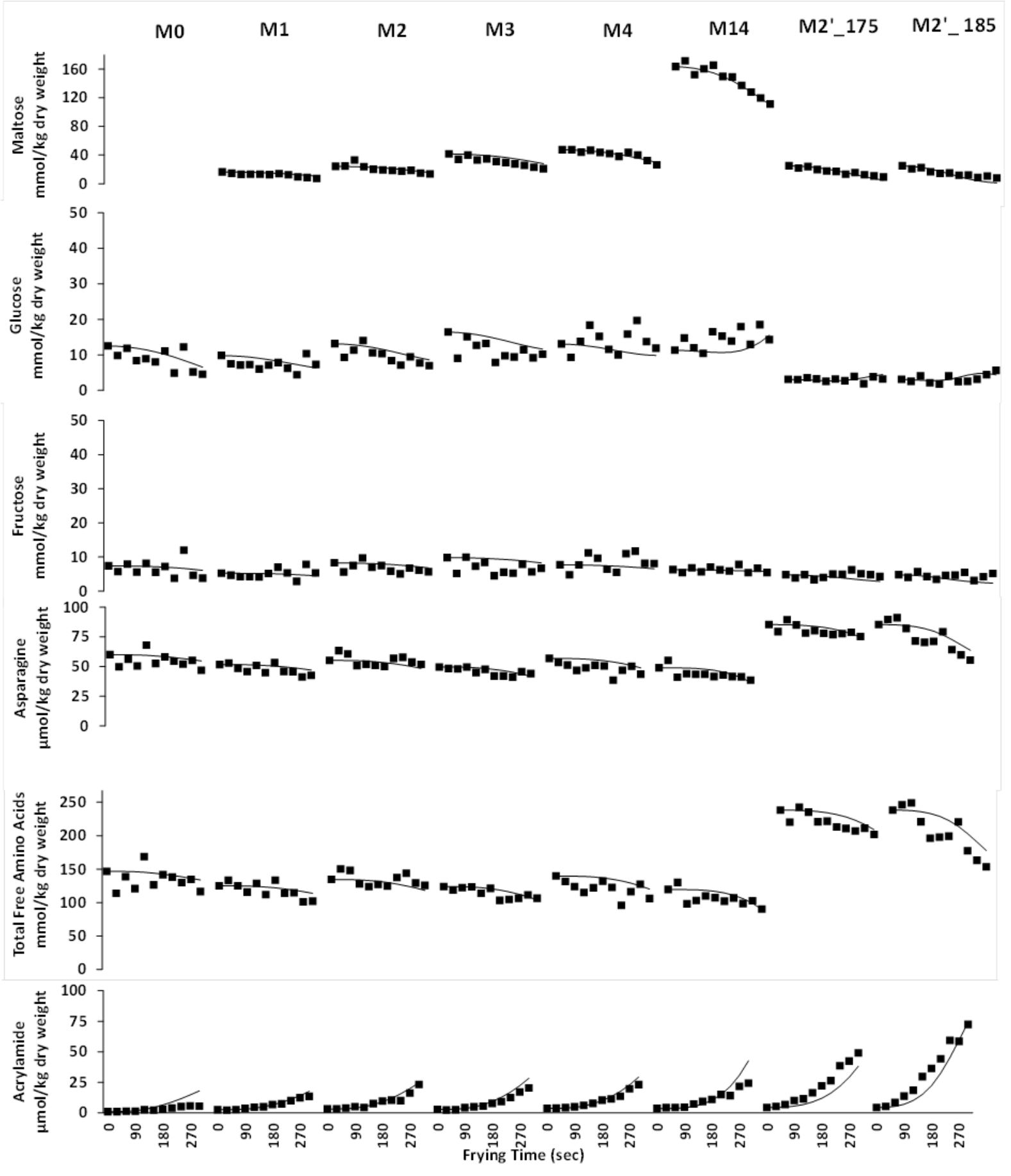

Figure S1 Maltose, glucose, fructose, asparagine, total free amino acids and acrylamide concentrations as a function of time (0-300 s) during finish-frying of eight batches of maltose-dipped potato strips at $165^{\circ} \mathrm{C}(\mathrm{M} 0, \mathrm{M} 1, \mathrm{M} 2, \mathrm{M} 3, \mathrm{M} 4$ and M14 represent $0,1,2,3,4$ and $14 \%$ dip respectively), $175^{\circ} \mathrm{C}\left(\mathrm{M} 2{ }^{\prime} \_175=2.0 \% \operatorname{dip}\right)$ and $185^{\circ} \mathrm{C}\left(\mathrm{M} 2{ }^{\prime} \_185=2.0 \% \operatorname{dip}\right)$. Symbols ( $\square$ ) are the experimental data points and the line (-) shows the kinetic Model 1 derived from the combined data set using Kinetic Mechanism 1 (Figure 2). 


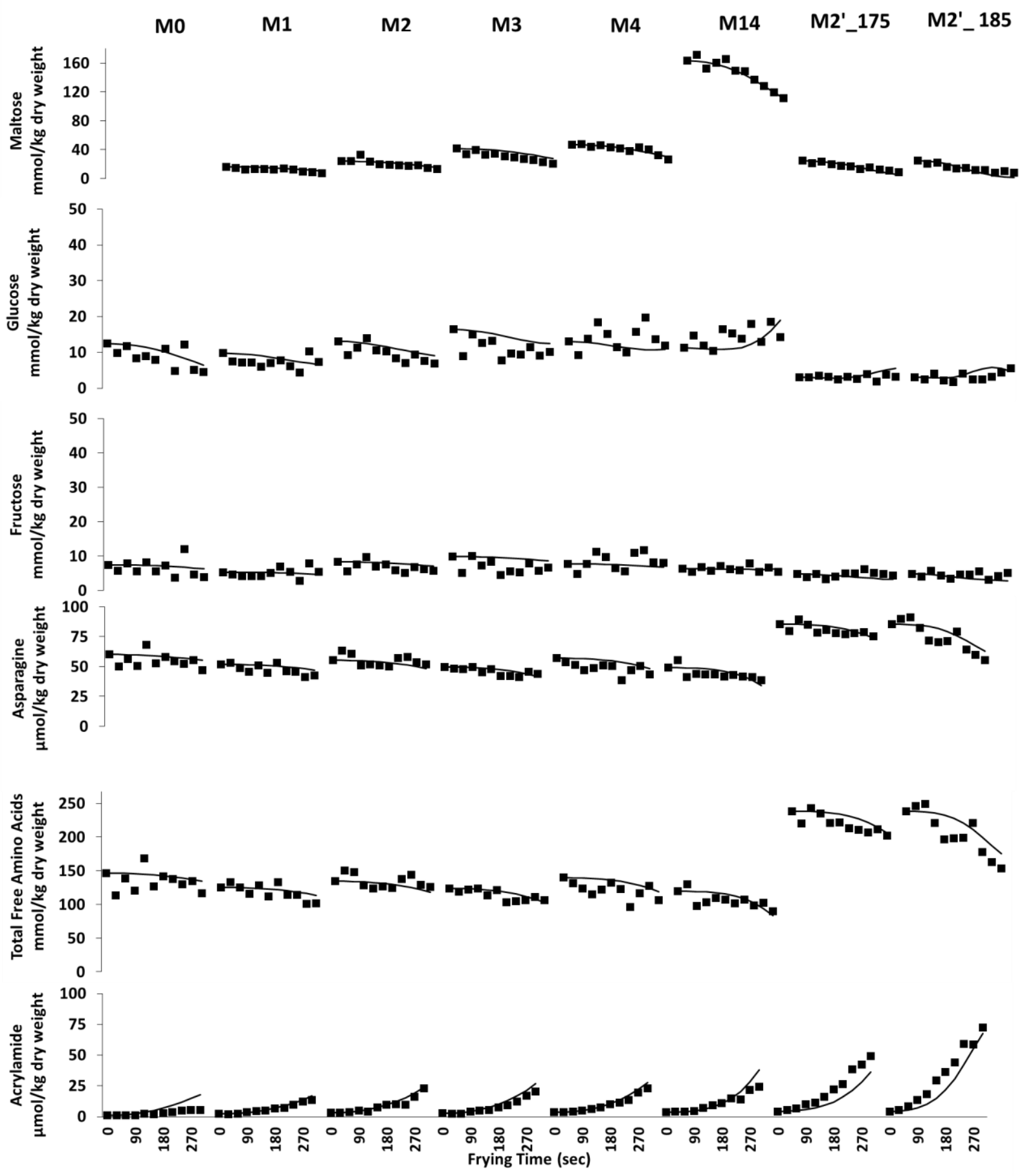

Figure S2. Maltose, glucose, fructose, total amino acids, and acrylamide concentrations as a function of time (0-5 min) during finish-frying of eight batches of maltose-dipped potato strips at $165{ }^{\circ} \mathrm{C}(\mathrm{M} 0$, $\mathrm{M} 1, \mathrm{M} 2, \mathrm{M} 3, \mathrm{M} 4$ and M14 represent $0,1,2,3,4$ and 14\% dip respectively), $175{ }^{\circ} \mathrm{C}\left(\mathrm{M} 2{ }^{\prime}{ }_{-} 175=2 \%\right.$ dip) and $185{ }^{\circ} \mathrm{C}\left(\mathrm{M}^{\prime}{ }_{-} 185=2 \%\right.$ dip $)$. Symbols ( $)$ are the experimental data points, and the line (-) shows kinetic model Model 2 derived from the combined data set using Kinetic Mechanism 2 (Figure 2). 


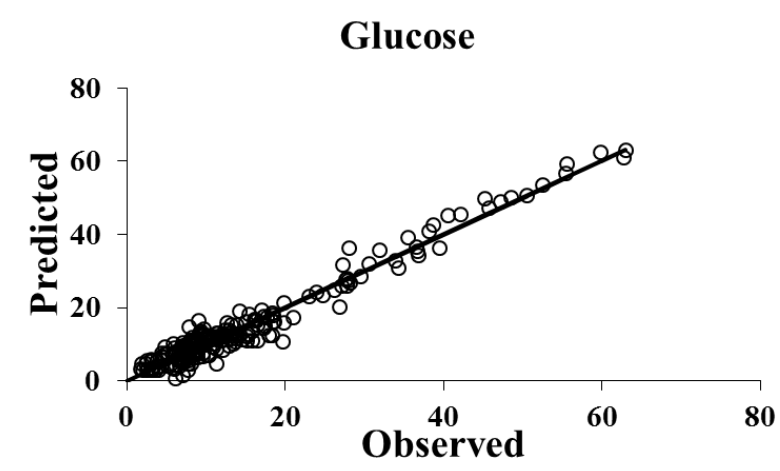

Free Amino Acids

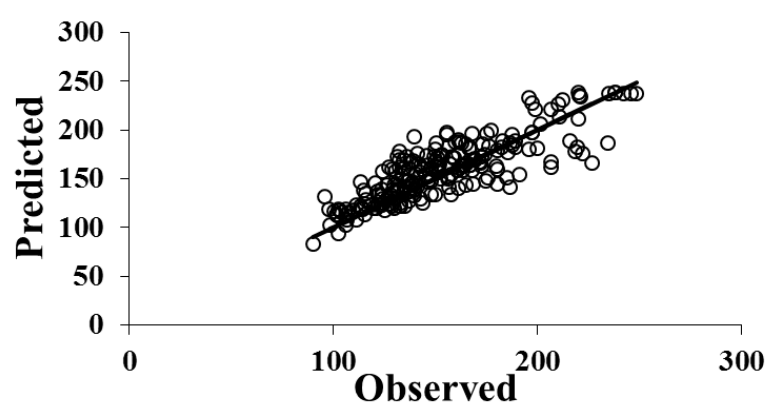

Maltose

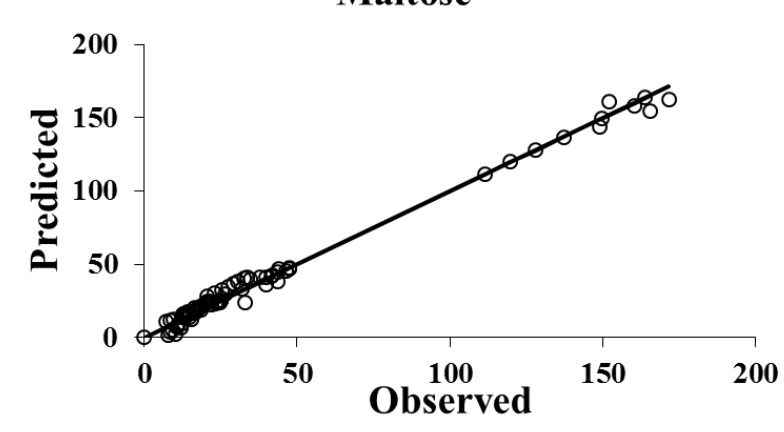

Fructose

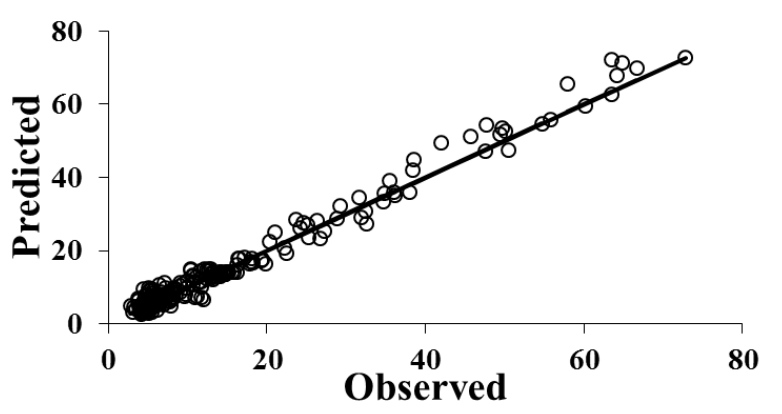

Acrylamide

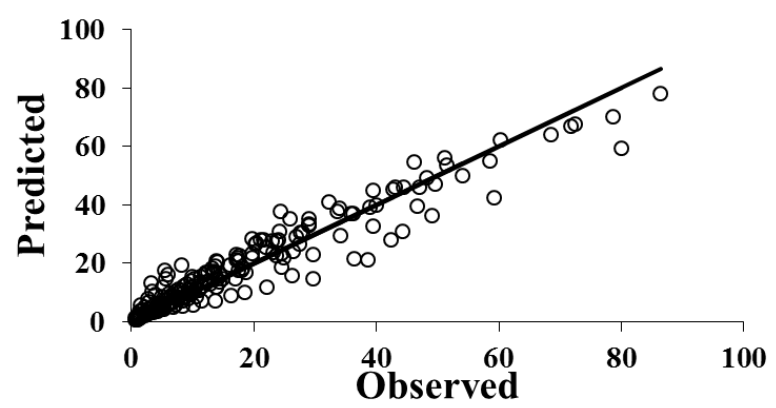

Asparagine

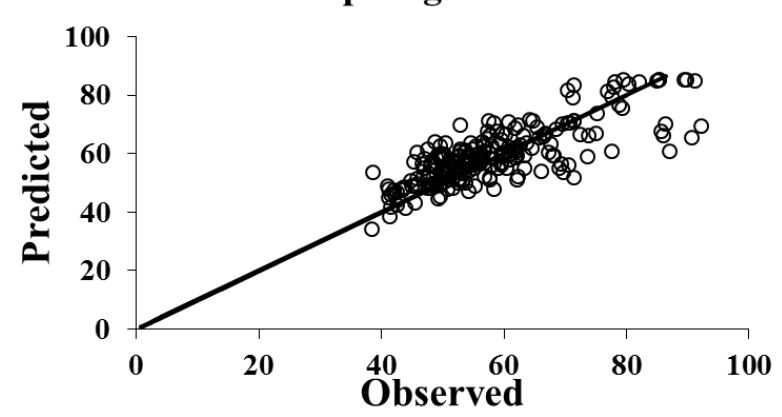

Figure S3. Predicted against observed values for Model 2 for all batches of fries compared with the line of perfect fit $(y=1)$. In all graphs the units are $\mathrm{mmol} / \mathrm{kg}$ fat-free dry weight, except acrylamide which is expressed as $\mu \mathrm{mol} / \mathrm{kg}$ fat-free dry weight. 